\title{
Accuracy of Integrated Multi-SatelliE Retrievals for GPM Satellite Rainfall Product over North Vietnam
}

\author{
Luong Bang Nguyen, Van Quang Do* \\ Thuyloi University, 175 Tay Son, Dong Da, Hanoi 100000, Vietnam
}

Received: 7 March 2021

Accepted: 14 May 2021

\begin{abstract}
Remote sensing of precipitation has been paid attention to recently for improving water resources estimation and hydrological applications. This study aims to assess one of the latest satellite rainfall product - Integrated Multi-satelliE Retrievals for GPM (IMERG) for Northern Vietnam. This study used the Tropical Rainfall Measurement Mission (TRMM), which is the predecessor of IMERG as a benchmark. The work consists of two parts: (i) comparison of IMERG and TRMM with rain gauge at a daily time scale; (ii) simulation of daily streamflow with IMERG-based and TRMM-based hydrological models. Four different precipitation metrics have been used to evaluate the IMERG and TRMM datasets, and the Soil and Water Assessment Tool (SWAT) hydrological model has been used in simulating daily streamflow at two river basins. The results indicated that IMERG did not significantly improve than TRMM when compared them with rain gauge. However, IMERG-based SWAT models were comparable with rain-gauge-based SWAT models in simulating daily streamflow. The TRMM-based SWAT models only produced reasonable results at one basin. Overall, the IMERG rainfall dataset can be an alternative rainfall dataset for Northern Vietnam with respect to estimated rainfall as well as input for hydrological simulation. This study provides useful information for environmental assessment, water resources management, and decision-making with support of remote sensing datasets.
\end{abstract}

Keywords: GPM IMERG, TRMM, Vietnam, satellite precipitation, SWAT

\section{Introduction}

Rain gauges are a traditional method to obtain rainfall information world-wide and they are considered as the 'true' measurement at point scale $[1,2]$. However,

*e-mail: quangkttl@tlu.edu.vn

a number of rain gauge stations have tended to decline in many regions around the globe, especially after 1990 due to maintenance cost and administration issues [3]. This causes challenges for monitoring precipitation trends in the near future if we only use rain gauge dataset.

Satellite-based precipitation products have experienced a fast-growing increase in the number of providers with longer timeseries (up to the 1980s), 
especially after 2000. However, remote sensing of precipitation is often evaluated as not sufficiently accurate because the satellites indirectly measure precipitation (e.g., estimate precipitation through cloud's temperature) [4]. Also, the quality of satellite-based precipitation products is not the same for different regions across the globe [5]. Therefore, before using satellite-based precipitation products, it is recommended that we should rigorously evaluate these products to examine whether it is suitable for a given study domain [6].

Tropical Rainfall Measurement Mission (TRMM) is the first satellite product to estimate rainfall within the tropical zone [7]. TRMM has been widely used in many hydrological application studies [8-11]. However, the main satellite for this mission ended its orbit in 2015. The successor of TRMM, Global Precipitation Mission (GPM), started from 2014 onward. Similar to TRMM, the GPM product is also a joint from multiple constellation [12]. Moreover, GPM exhibits more advantages than TRMM considering its (i) higher spatial resolution $\left(0.1^{\circ}\right.$ against $\left.0.25^{\circ}\right)$; (ii) higher temporal resolution (half-hour versus three-hour); (iii) higher radar frequency; (iv) ability to provide data for extreme weather predictions [13, 14]. Although GPM's main satellite was just launched in 2014, high resolution GPM precipitation was extended back to 2000 [15].

The grid level 3 of GPM - Integrated Multi-satelliE Retrievals for GPM (IMERG) - is the final product for end users. There are several previous studies which evaluated the performance of IMERG precipitation products. In a comparative hydrological simulations study to assess eight different satellite-based precipitation products over Vietnam, Le et al., 2020 [6] indicated that GPM Integrated Multi-satelliE Retrievals for GPM Final Version 6 (IMERG Final V6) exhibited the best overall performances. Yu, 2020 [16] presented a comprehensive study in comparing IMERG with other three satellite-based rainfall products over the Taihang Mountains of North China. This study reported a lower False Alarm Ratio and a higher correlation between IMERG and rain gauge data, compared to other products. In a catchment in Poland, radar and IMERGbased rainfall estimates provided the most reliable precipitation measurements as input for a hydrological model [17]. Ehsan and Hatim, 2018 [18] carried on an evaluation study for IMERG at its uncalibrated and calibrated products over the Lower Colorado River Basin of Texas. This study reported that these IMERG products exhibited a great potential for applications in water resources management and flood forecasting. However, there are still uncertainties on spatial pattern and accuracy of IMERG [18], snowfall estimation [19], and storm capture [20].

Vietnam shares a large amount of its water resources with other countries (up to 60\%) [21]. With a limited ground data sharing among Vietnam and the upstream countries, it is essential to seek remote-based rainfall sources to better understand its rainfall variation in space. However, there are few studies on remote sensing of precipitation over Vietnam [10, 6, 22, 23].

This study aims to assess IMERG Final Run Version 6 for Northern Vietnam. The TRMM 3B42 V7 has been used as a benchmark to examine the improved performance of IMERG during a period from 2007 to 2014. This study proposed two objectives to evaluate IMERG. Firstly, this study compared IMERG and TRMM 3B42V7 with rain gauge data in the study domain at a daily time step. Secondly, all satellitebased products and rain gauges were used as input for the SWAT (Soil and Water Assessment Tool) hydrological model [24] at a daily time step. This study selected two basins located in Northern Vietnam for a hydrological assessment purpose. The SWAT model has exhibited strong capacities in hydrological assessment across Vietnam [25, 6, 26, 27]. In this study, Section 2 introduces Case Study. Section 3 presents Data and Methodology. Results and discussion and Conclusions are given in Section 4 and Section 5, respectively.

\section{Case Study}

\section{Study Area}

Northern Vietnam includes 25 provinces with an area of $120,000 \mathrm{~km}^{2}$, with a population of 35 million people (2019 figure). Northern Vietnam's topography is complex with a high to low altitude gradient from Northwest to Southeast. The region has a tropical climate with two distinct seasons. The wet season is from May to October whereas the dry season is from November to April. Average annual precipitation varies greatly. The Northwest region has an average annual rainfall of 1,200-2,000 mm, the Northeast region has an average annual rainfall of 1,400-2,000 $\mathrm{mm}$, and the lowland area in Southeast receives an average annual rainfall of 1,400-1,800 $\mathrm{mm}$ [28]. Precipitation investigations in North Vietnam are needed for society developments and water resource management because the region encompasses (i) Vietnam's capital (Hanoi) with a dense population and the country's core economy, (ii) diverse climate with complex terrain, (iii) the second largest river of Vietnam-Hong Thai Binh River basin.

\section{Data and Methodology}

\section{Ground Data}

Observed hydro-meteorological datasets were obtained from the Vietnam Meteorological and Hydrological Administration (VMHA). These datasets passed quality checks and are considered reliable for use. This study collected daily 2007-2014 precipitation data from 53 rain gauge stations across northern Vietnam (see Supplementary Material 1). Daily streamflow data corresponding to two river basins (Langson and Xala), 


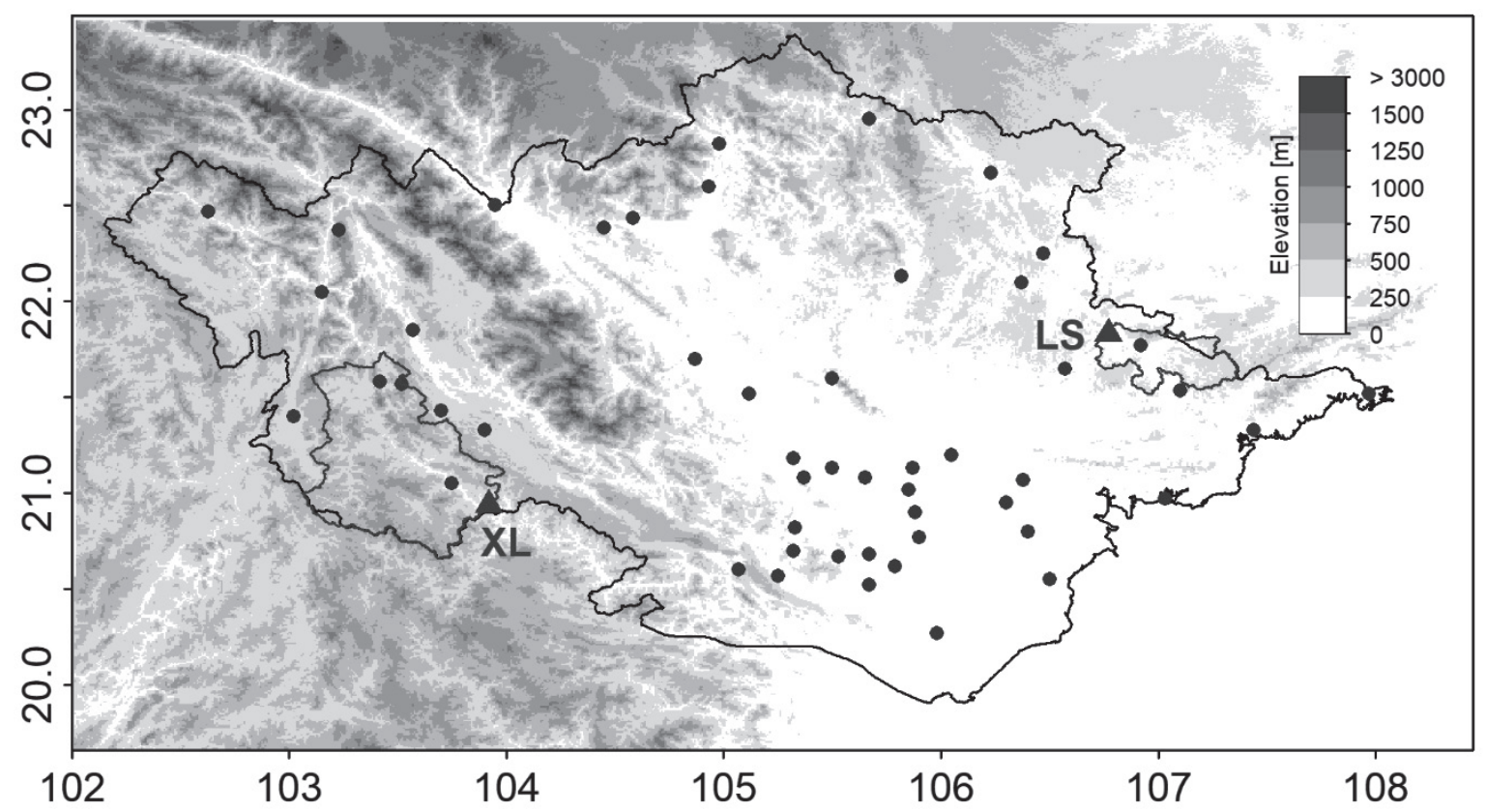

Fig. 1. Digital Elevation Model (DEM) and distribution of rain gauge sites (blue dots) used in this study over North Vietnam. Dark red triangular points denote location of two hydrological stations Langson (LS) and Xala (XL). Dark red boundaries denote the basin boundaries of LS and XL.

located entirely in northern Vietnam, were collected from 2008-2014 (Fig. 1). Langson basin (Ky Cung River) has an area of $1,560 \mathrm{~km}^{2}$ while Xala basin (Ma River) has an area of $6,430 \mathrm{~km}^{2}$. The purpose of this collection is to evaluate the streamflow simulations using different rainfall inputs. Additionally, this study collected one temperature station at Langson basin and two temperature stations at Xala basin. These temperature stations, along with rainfall datasets, are forced to a hydrological model.

\section{Remote Sensing of Precipitation}

Launched in late 1997, the Tropical Rainfall Measurement Mission (TRMM) Multi-satellite Precipitation Analysis (TMPA) is a collaboration between the National Aeronautics and Space Administration (NASA) and the Japan Aerospace Exploration Agency (JAXA). It is the first mission to measure rainfall in tropical regions from space [7]. Among TMPA products, this study used the research product version TMPA 3B42V7 [12]. The three hours $0.25^{\circ}$ grid TMPA 3B42V7 was accessed from NASA's Goddard Space Flight Center website (https://pmm.nasa. gov/data-access/downloads/trmm). The TMPA 3B42V7 dataset was then accumulated to a daily time step. Note that daily observation rainfall from a rain gauge in Vietnam is accumulated from the previous 19.00 to the current $19.00(\mathrm{GTM}+7)$. Daily TMPA 3B42V7 contains 8 bins GTM $+7(00 \mathrm{tz}, 03 \mathrm{tz}, \ldots, 21 \mathrm{tz})$. Therefore, to match daily TMPA 3B42V7 with rain gauge data, daily TMPA $3 \mathrm{~B} 42 \mathrm{~V} 7$ was accumulated from previous day 12 tz to current day $9 \mathrm{tz}$.
The Global Precipitation Measurement (GPM) mission is a successor of the TRMM mission. The Integrated Multi-satellitE Retrievals for GPM (IMERG) product, the Level 3 multi-satellite precipitation algorithm of GPM [13], provided a $10 \mathrm{~km}$ grid rainfall at every 30 mins from June 2000 to present. The research product IMERG Final Run Version 6 has been used in this study and obtained from NASA's Goddard Space Flight Center website (https://pmm.nasa.gov/dataaccess/downloads/gpm). To match daily IMERG Final Run Version 6 with rain gauge data, daily IMERG Final Run Version 6 was accumulated from previous day $12 \mathrm{tz}$ to current day 11.30tz (48 bins for a day).

Since TMPA 3B42V7 and IMERG Final run V6 have different spatial resolutions $\left(0.25^{\circ}\right.$ vs. $\left.0.10^{\circ}\right)$, this study also evaluated IMERG at the similar resolution to TMPA 3B42V7 (reduction of spatial resolution from $0.10^{\circ}$ to $0.25^{\circ}$ using bilinear interpolation). In short, this study assessed three satellite-based precipitation products with rain gauge data, including (1) TMPA 3B42V7 $0.25^{\circ}$ (hereafter 3B42V7_025); (2) IMERG Final Run V6 $0.25^{\circ}$ (hereafter IMERG 025); (3) IMERG Final Run V6 $0.10^{\circ}$ (hereafter IMERG_010). Note that the use of 3B42V7_025, in this study, is a benchmark dataset to examine the improvement of IMERG.

\section{SWAT Model and Setup}

SWAT (Soil and Water Assessment Tool) is a physically based, semi-distributed model to simulate various hydrological variables (i.e., streamflow, sediment, water quality) of river basins [29]. In order to simulate the above hydrological variables, the SWAT 
Table 1. Description of precipitation and streamflow performance metrics.

\begin{tabular}{|c|c|c|c|}
\hline Metrics & Statistic & Equation & Optimal value \\
\hline \multirow{4}{*}{$\begin{array}{c}\text { Precipitation } \\
\text { performance metrics }\end{array}$} & $P O D$ & $\frac{N_{11}}{N_{11}+N_{01}}$ & 1 \\
\hline & $F A R$ & $\frac{N_{10}}{N_{11}+N_{10}}$ & 0 \\
\hline & $C C$ & $\frac{\sum_{i=1}^{N}\left(R G_{i}-\overline{R G}\right)\left(S A T_{i}-\overline{S A T}\right)}{\sqrt{\sum_{i=1}^{N}\left(R G_{i}-\overline{R G}\right)^{2} \sum_{i=1}^{N}\left(S A T_{i}-\overline{S A T}\right)^{2}}}$ & 1 \\
\hline & $R M S E$ & $\sqrt{\frac{1}{N} \sum_{i=1}^{N}\left(S A T_{i}-R G_{i}\right)^{2}}$ & 0 \\
\hline \multirow{2}{*}{$\begin{array}{c}\text { Streamflow } \\
\text { performance metrics }\end{array}$} & $N S E$ & $1-\frac{\sum_{i=1}^{N}\left(O B S_{i}-S I M_{i}\right)}{\sum_{i=1}^{N}\left(O B S_{i}-\overline{O B S}\right)^{2}}$ & 1 \\
\hline & PBIAS & $1-\frac{\sum_{i=1}^{N}\left(O B S_{i}-S I M_{i}\right)}{\sum_{i=1}^{N} O B S_{i}}$ & 0 \\
\hline
\end{tabular}

Note: $N_{11}$ represents the precipitation observed by the rain gauge and satellite simultaneously. $N_{10}$ represents the precipitation observed by the satellite, but not observed by the rain gauge. $N_{01}$ is contrary to $N_{10} . R G$ and $S A T$ present rain gauge and satellite precipitation estimates, respectively. $O B S_{i}$ is observed streamflow $\left(\mathrm{m}^{3} / \mathrm{s}\right)$ at the ith day, $S I M_{i}$ is simulated streamflow $\left(\mathrm{m}^{3} / \mathrm{s}\right)$ at the ith day. $\overline{O B S}$ and $\overline{S I M}$ are average observed streamflow and average simulated streamflow, respectively.

model requires various inputs, including meteorological data (precipitation, maximum temperature, minimum temperature), elevation, land use, and soil properties. The $90 \mathrm{~m}$ Multi-Error-Removed Improved-Terrain Digital Elevation Model (MERIT DEM) was used to estimate the slope and delineate the basin boundary; it was obtained from the MERIT DEM website (http:// hydro.iis.u-tokyo.ac.jp/ yamadai/MERIT_DEM/). The MERIT DEM is a corrected dataset that combines two existent DEMs NASA SRTM DEM and JAXA AW3D DEM. Therefore, we used this DEM to expect increasing the accuracy of watershed delineation. With respect to land use data, this study obtained a land use map from 2010 via the land use portal for the Lower Mekong Basin (https://rlcms-servir.adpc.net/en/ landcover/), which covers entirely northern Vietnam. The soil properties for two river basins were obtained from a soil map of the Vietnam National Institute for Soil and Fertilizer [30].

By changing precipitation input datasets, including ground observation; 3B42V7_025; IMERG_025; IMERG_010; four simulations were established for each basin to analyze the impacts of different rainfall inputs on streamflow simulation. This study selected the first year (2007) as the warm-up period, the next four years (2008-2011) as the calibration period, and the last three years (2012-2014) as the validation period. The SWATCUP tool with the Sequential Uncertainty Fitting algorithm version 2 (SUFI-2) algorithm [31] has been used to calibrate the model. The calibration process

Table 2. Variation of annual rainfall estimated by rain gauge and satellite rainfall products during 2007-2014.

\begin{tabular}{|c|c|c|c|c|c|c|c|}
\hline Year & Rain gauge & 3B42V7_025 & IMERG_025 & IMERG_010 & $\begin{array}{c}\text { Pbias of } \\
\text { 3B42V7_025 }\end{array}$ & $\begin{array}{c}\text { Pbias of } \\
\text { IMERG_025 }\end{array}$ & $\begin{array}{c}\text { Pbias of } \\
\text { IMERG_010 }\end{array}$ \\
\hline 2007 & $1641(561)$ & $1625(270)$ & $1616(206)$ & $1608(215)$ & -1.0 & -1.5 & -2.0 \\
\hline 2008 & $2108(602)$ & $2159(260)$ & $2192(210)$ & $2185(206)$ & 2.4 & 4.0 & 3.7 \\
\hline 2009 & $1527(452)$ & $1551(276)$ & $1541(213)$ & $1529(202)$ & 1.6 & 0.9 & 0.1 \\
\hline 2010 & $1588(536)$ & $1597(206)$ & $1577(146)$ & $1572(143)$ & 0.6 & -0.7 & -1.0 \\
\hline 2011 & $1627(422)$ & $1631(227)$ & $1696(213)$ & $1691(212)$ & 0.2 & 4.2 & 3.9 \\
\hline 2012 & $1871(498)$ & $1841(202)$ & $1836(194)$ & $1824(190)$ & -1.6 & -1.9 & -2.5 \\
\hline 2013 & $1959(563)$ & $1926(277)$ & $1974(201)$ & $1971(213)$ & -1.7 & 0.8 & 0.6 \\
\hline 2014 & $1615(573)$ & $1742(290)$ & $1717(196)$ & $1707(203)$ & 7.9 & 6.3 & 5.7 \\
\hline
\end{tabular}


was carried out for each rainfall input set with 1000 simulation runs.

\section{Precipitation Performance Metrics}

With respect to direct evaluation which compares satellite-based precipitation datasets with rain gauge data, this study used four metrics [32, 9], including i) Probability of Detection (POD); ii) False Alarm Ratio (FAR); iii) Correlation Coefficient (CC); and iv) Root Mean Square Error (RMSE). The POD provides the ratio of the total precipitation events, which satellite precipitation estimates detect among the actual precipitation events. The FAR evaluates the fraction of false rainfall events, detected by satellite precipitation estimates from the total rainfall events. The CC is a score of the similarity between the satellite precipitation estimates and ground observations, while the RMSE demonstrates the bias and error of satellite estimates. The formulae and perfect scores for satellite precipitation estimates metrics are given in Table 1.

\section{Streamflow Performance Metrics}

With respect to the indirect evaluation, which evaluates streamflow simulation using the SWAT model with different rainfall inputs, this study considered i) Nash-Sutcliffe Efficiency (NSE) and ii) Percentage

a) 3B42V7_025
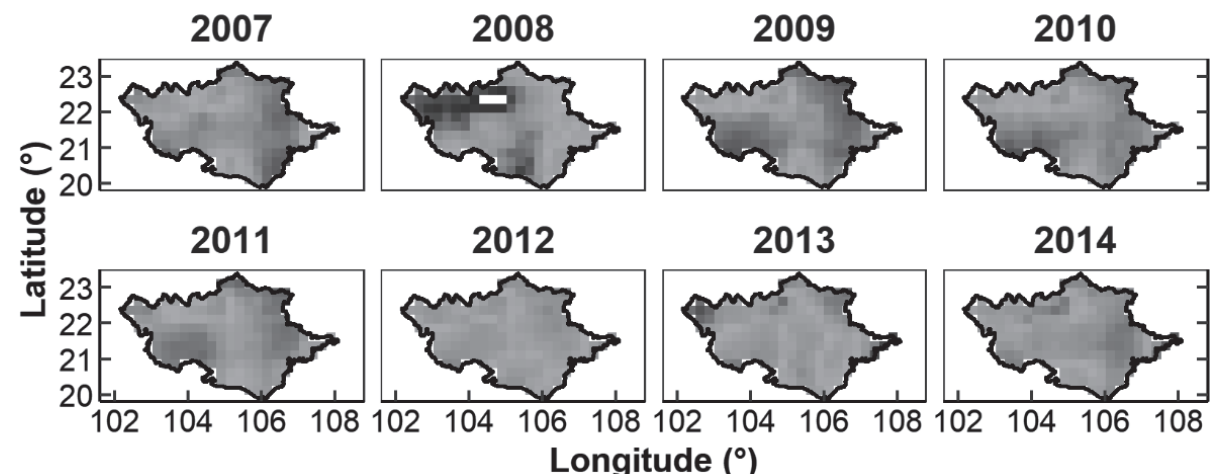

Rainfall

(mm)

2600

2400

2200

2000

1800

1600

1400

1200

b) IMERG_025
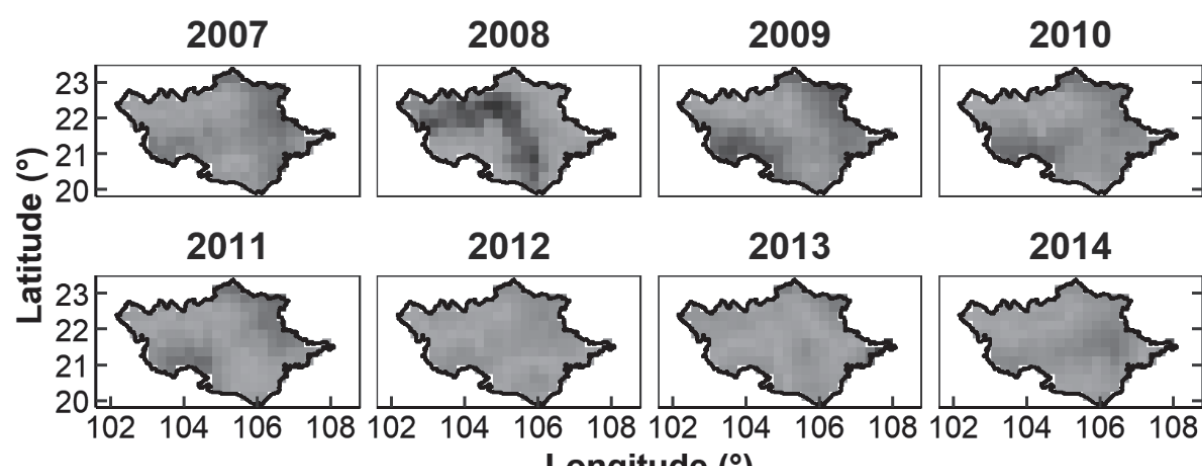

Rainfall

(mm)

2600

2400

2200

2000

1800

1600

1400

1200

c) IMERG_010
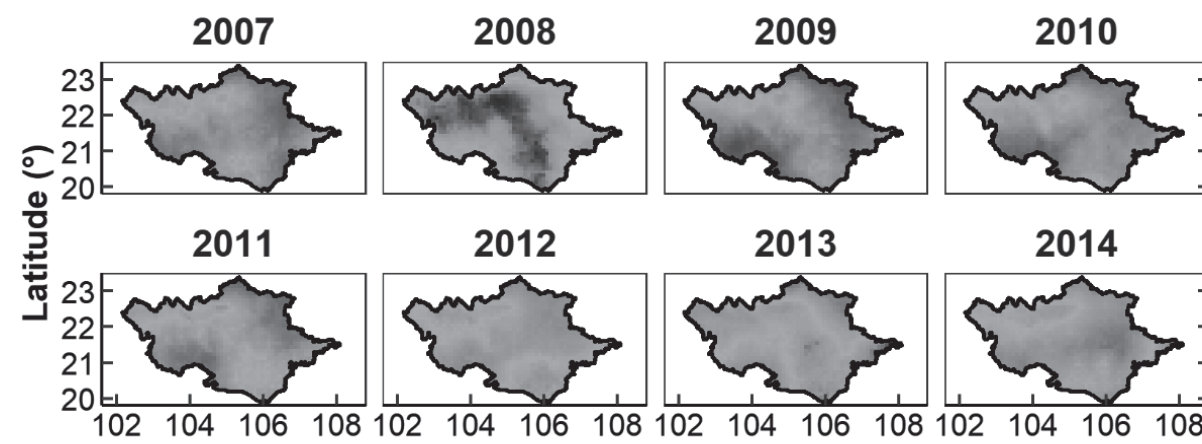

Rainfall

(mm)

2600

2200

2000

1800

1600

1400

1200

\section{Longitude $\left({ }^{\circ}\right)$}

Fig. 2. Annual rainfall distribution over North Vietnam during 2007-2014 based on a) 3B42V7_025; b) IMERG_025; and c) IMERG_010 datasets. 
Bias (PBIAS) [33]. The NSE indicates the degree of the observed streamflow and the simulated streamflow fits the 1:1 line. The PBIAS measures the percentage average difference of the simulated streamflow to its observed counterpart. The formulae and perfect scores for streamflow performance metrics are given in Table 2 .

\section{Results and Discussion}

\section{Annual Rainfall Variation During 2007-2014}

Table 2 presents annual rainfall characteristics from rain gauge, 3B42V7 025, IMERG 025, and IMERG_010 during 2007-2014. All satellite-based rainfall products estimated closely with average annual rain gauge values. The highest difference between rainfall measured from rain gauge and satellitebased products was found in 2014 with $7.9 \%, 6.3 \%$, and 5.7\% PBIAS for 3B42V7 025, IMERG 025, and IMERG_010, respectively.

Fig. 2 shows spatial variation of rainfall for 3B42V7 025, IMERG 025, and IMERG_010, respectively. All satellite-based products exhibited noticeably high rainfall in 2008 which corresponded to a very wet season in North Vietnam. In the upcoming two years 2009-2010, the region suffered a prolonged drought and that was also reflected by the remote sensing of precipitation datasets by the lowest rainfall received among the given study time period [34]. It is noticed that all satellite-based products gave similar rainfall patterns, however, IMERG_010 provided higher rainfall details at $10 \mathrm{~km}$.

\section{Evaluation of Statistical Precipitation Metrics}

Statistical metrics for three satellite rainfall products are given in Table 3 during the dry season, the wet season, and the entire period. Generally, IMERG 025 and IMERG 010 exhibited better correlation coefficient scores than 3B42V7 025, typically in the wet season. Interestingly, in the $\overline{d r y}$ season, 3B42V7_025 exhibited slightly better than IMERG products. It was also a similar observation to RMSE. In a comparison between IMERG 025 and IMERG 010, the upscaled product IMERG 025 was comparable with IMERG 010.

Fig. 3 shows spatial CC and RMSE scores of three satellite rainfall products over North Vietnam during 2007-2014. Stations in high mountains areas of the northwest case study generally exhibited lower scores than the rest.

Table 3. Median values Correlation Coefficient (CC) and Root Mean Square Error (RMSE) for 3B42V7_025, IMERG_025, and IMERG_010, in comparison with rain gauge during 2007-2014. Higher CC and smaller absolute RMSE indicate better performances. Bold values are the best value.

\begin{tabular}{|c|c|c|c|c|c|c|c|c|c|}
\hline Metrics & \multicolumn{3}{|c|}{ All } & \multicolumn{3}{c|}{ Dry } & \multicolumn{3}{c|}{ Wet } \\
\hline & 3B42V7_025 & $\begin{array}{c}\text { IM- } \\
\text { ERG_025 }\end{array}$ & $\begin{array}{c}\text { IM- } \\
\text { ERG_010 }\end{array}$ & 3B42V7_025 & $\begin{array}{c}\text { IM- } \\
\text { ERG_025 }\end{array}$ & $\begin{array}{c}\text { IM- } \\
\text { ERG_010 }\end{array}$ & 3B42V7_025 & $\begin{array}{c}\text { IM- } \\
\text { ERG_025 }\end{array}$ & $\begin{array}{c}\text { IM- } \\
\text { ERG_010 }\end{array}$ \\
\hline CC & 0.621 & 0.661 & $\mathbf{0 . 6 8 4}$ & $\mathbf{0 . 6 6 4}$ & 0.632 & 0.637 & 0.589 & 0.639 & $\mathbf{0 . 6 5 6}$ \\
\hline RMSE & 12.5 & $\mathbf{1 1 . 7}$ & $\mathbf{1 1 . 7}$ & 5.7 & 5.4 & $\mathbf{5 . 3}$ & 16.6 & $\mathbf{1 5 . 4}$ & 15.6 \\
\hline
\end{tabular}

a)

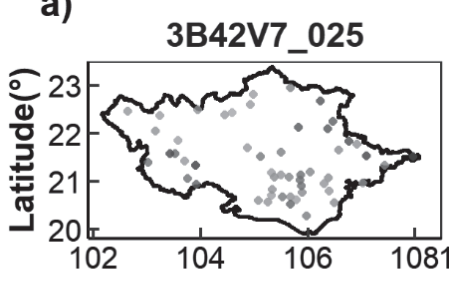

b)

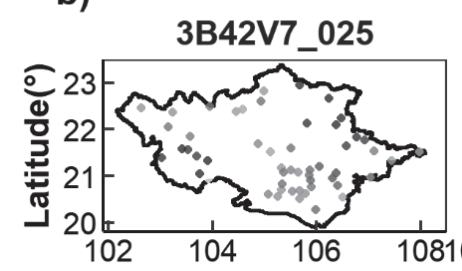

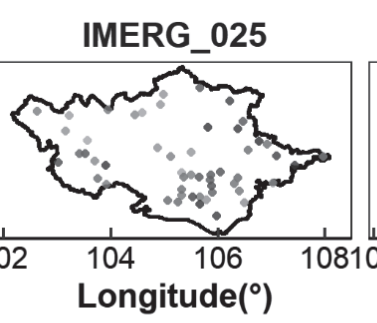

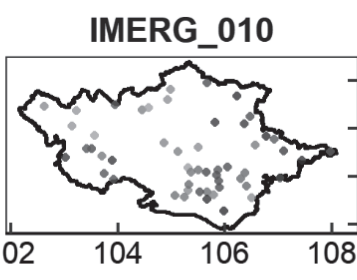

IMERG_025

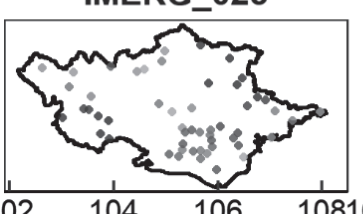

Longitude $\left({ }^{\circ}\right)$

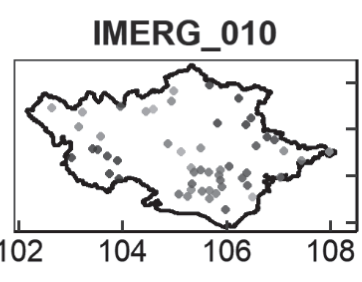

RMSE

$(\mathrm{mm})$

25

20

15

10

Fig. 3. a) Correlation Coefficient and b) RMSE for three satellite rainfall products (3B42V7_025, IMERG_025, and IMERG_010) against rain gauge over North Vietnam during 2007-2014. 
Table 4. Median values Probability of Detection (POD) and False Alarm Ratio (FAR) for 3B42V7_025, IMERG_025, and IMERG_010, in comparison with rain gauge during 2007-2014. Higher POD and smaller FAR indicate better performances. Bold values are the best value.

\begin{tabular}{|c|c|c|c|c|c|c|c|c|c|}
\hline Metrics & \multicolumn{3}{|c|}{ All } & \multicolumn{3}{c|}{ Dry } & \multicolumn{3}{c|}{ Wet } \\
\hline & 3B42V7_025 & $\begin{array}{c}\text { IM- } \\
\text { ERG_025 }\end{array}$ & $\begin{array}{c}\text { IM- } \\
\text { ERG_010 }\end{array}$ & 3B42V7_025 & $\begin{array}{c}\text { IM- } \\
\text { ERG_025 }\end{array}$ & $\begin{array}{c}\text { IM- } \\
\text { ERG_010 }\end{array}$ & 3B42V7_025 & $\begin{array}{c}\text { IM- } \\
\text { ERG_025 }\end{array}$ & $\begin{array}{c}\text { IM- } \\
\text { ERG_010 }\end{array}$ \\
\hline POD & 0.646 & $\mathbf{0 . 7 2 0}$ & $\mathbf{0 . 7 2 0}$ & 0.309 & 0.421 & $\mathbf{0 . 4 2 2}$ & 0.794 & 0.847 & $\mathbf{0 . 8 5 3}$ \\
\hline FAR & $\mathbf{0 . 3 0 5}$ & 0.357 & 0.354 & $\mathbf{0 . 3 2 6}$ & 0.428 & 0.407 & $\mathbf{0 . 3 0 7}$ & 0.344 & 0.339 \\
\hline
\end{tabular}

a)
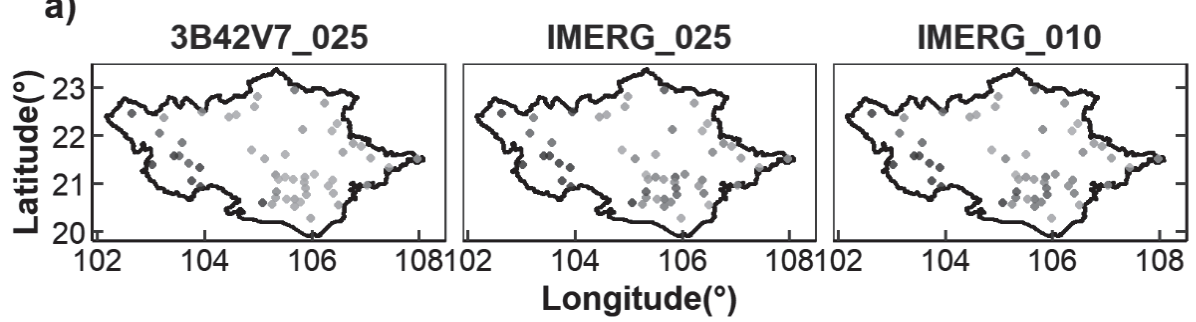

POD

b)
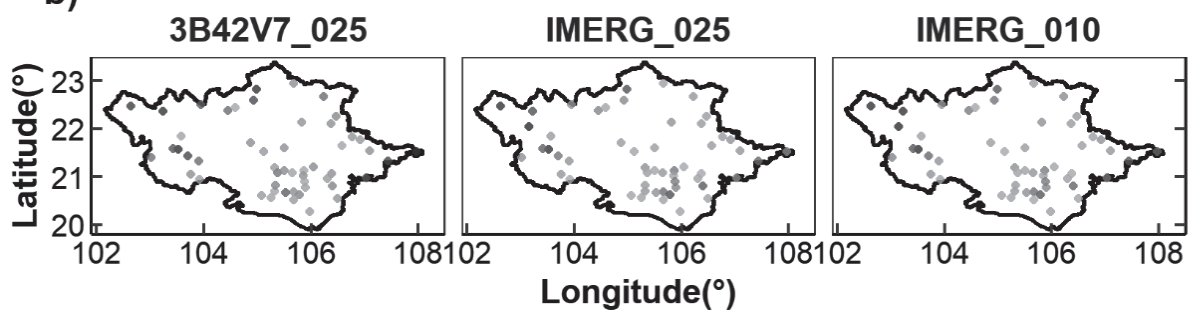

FAR

0.5

0.4

0.3

0.2

Fig. 4. a) POD and b) FAR for three satellite rainfall products (3B42V7_025, IMERG_025, and IMERG_010) against rain gauge over North Vietnam during 2007-2014.

\section{Evaluation of Detection Precipitation Metrics}

Detection metrics for three satellite rainfall products are given in Table 4 during the dry season, the wet season, and the entire period. IMERG_025 and IMERG_010 exhibited better rates of rainfall detection (higher POD), compared to these figures of 3B42V7 025. However, rates of false detection (FAR) in IMERG products were larger than 3B42V7 025. The FAR scores of IMERG products (both $0.25 \mathrm{deg}$ and $0.10 \mathrm{deg}$ ) were high in the southeastern part of the case study (Fig. 4). With respect to this sense, IMERG products are likely to estimate a higher number of rainfall days. However, this is prone to a high chance in detecting inaccurate rainfall events.

\section{Relationship between Elevation and Satellite Data Error}

This study grouped rainfall stations in three elevation zones i) $0-50 \mathrm{~m}$, ii) $50-400 \mathrm{~m}$, and iii) $>400 \mathrm{~m}$. Statistical metrics (CC and RMSE); and detection metrics (POD and FAR) were calculated for each above elevation zone (Fig. 5). The results indicate that CC were not significant differences at different elevations. POD, RMSE and FAR were better at higher altitudes (higher POD, and lower RMSE and FAR) when we move up to higher elevation.

\section{Streamflow Simulation}

Figs 6-7 present the temporal variation between observed streamflow and simulated streamflow based on rain gauge, 3B42V7_025, IMERG_025, and IMERG 010 at Xala and Langson basin. For the NSE scores, the overall best performance was granted for rain gauge-driven simulation, followed by the IMERG_010driven simulation. During the validation period (20122014), the model forced with rain gauge exhibited 'Good' performances for both Xala and Langson basin [33]. The model forced with IMERG_010 exhibited 'Good' and 'Satisfactory' performances for Xala and Langson basin, respectively. The model forced with 3B42V7 025 exhibited 'Good' and 'Not Satisfactory' performances for Xala and Langson basin, respectively.

With respect to streamflow simulation bias, 3B42V7_025 and IMERG_025-driven simulations exhibited a high bias in simulating streamflow at Xala basin (|PBIAS $\mid>15 \%$ for both calibration and validation period). However, IMERG_010 driven simulation showed a lower bias in calibration period. For all simulations at Langson basin, all models driven by 

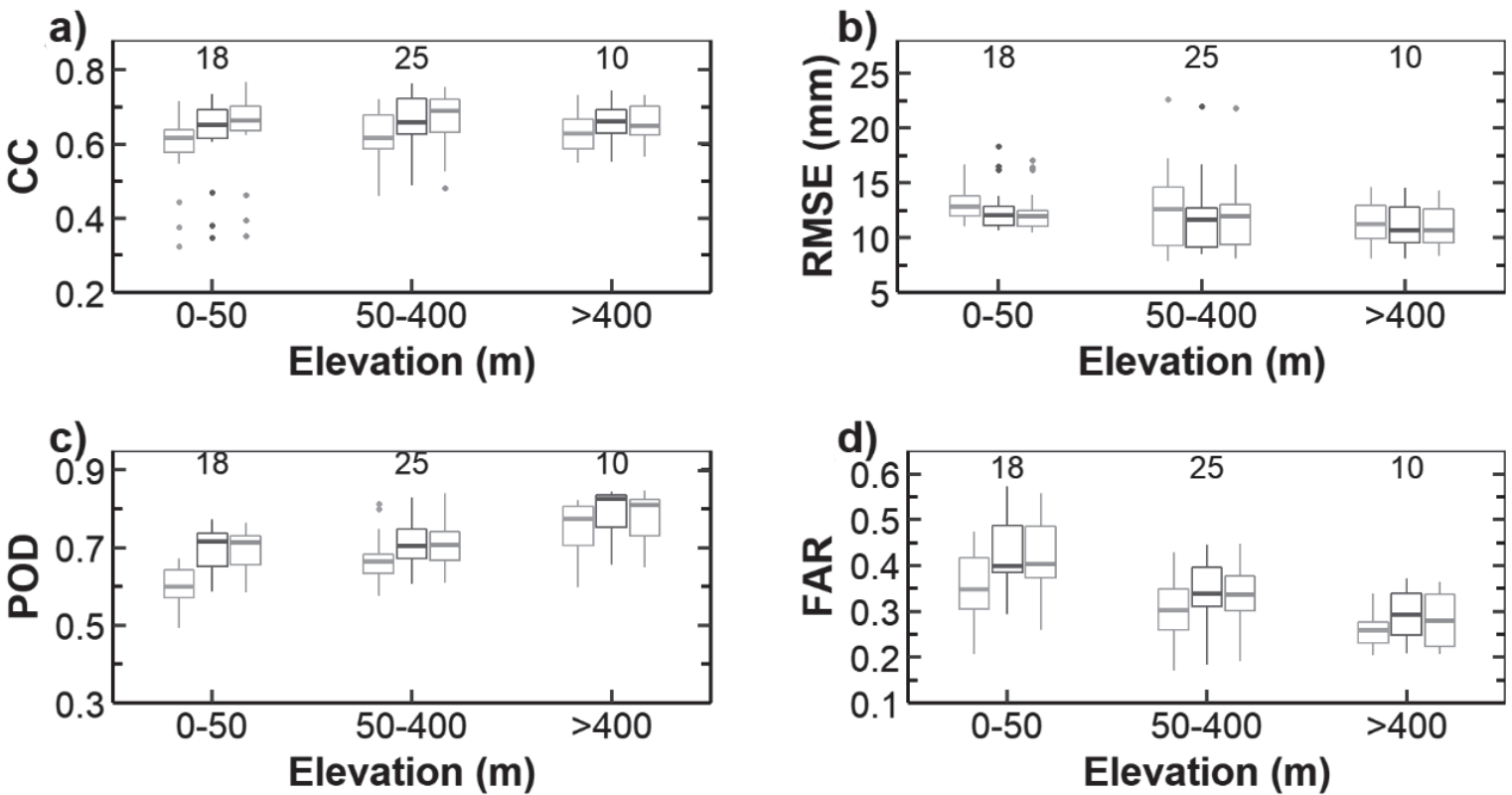

Fig. 5. Boxplot of relationship between a) CC, b) RMSE, c) POD, and (d) FAR and elevation. Red-, green-, and blue- boxplot represent 3B42V7_025, IMERG_025, and IMERG_010, respectively. Figures on the top boxplot denote the number of samples for each box plot.
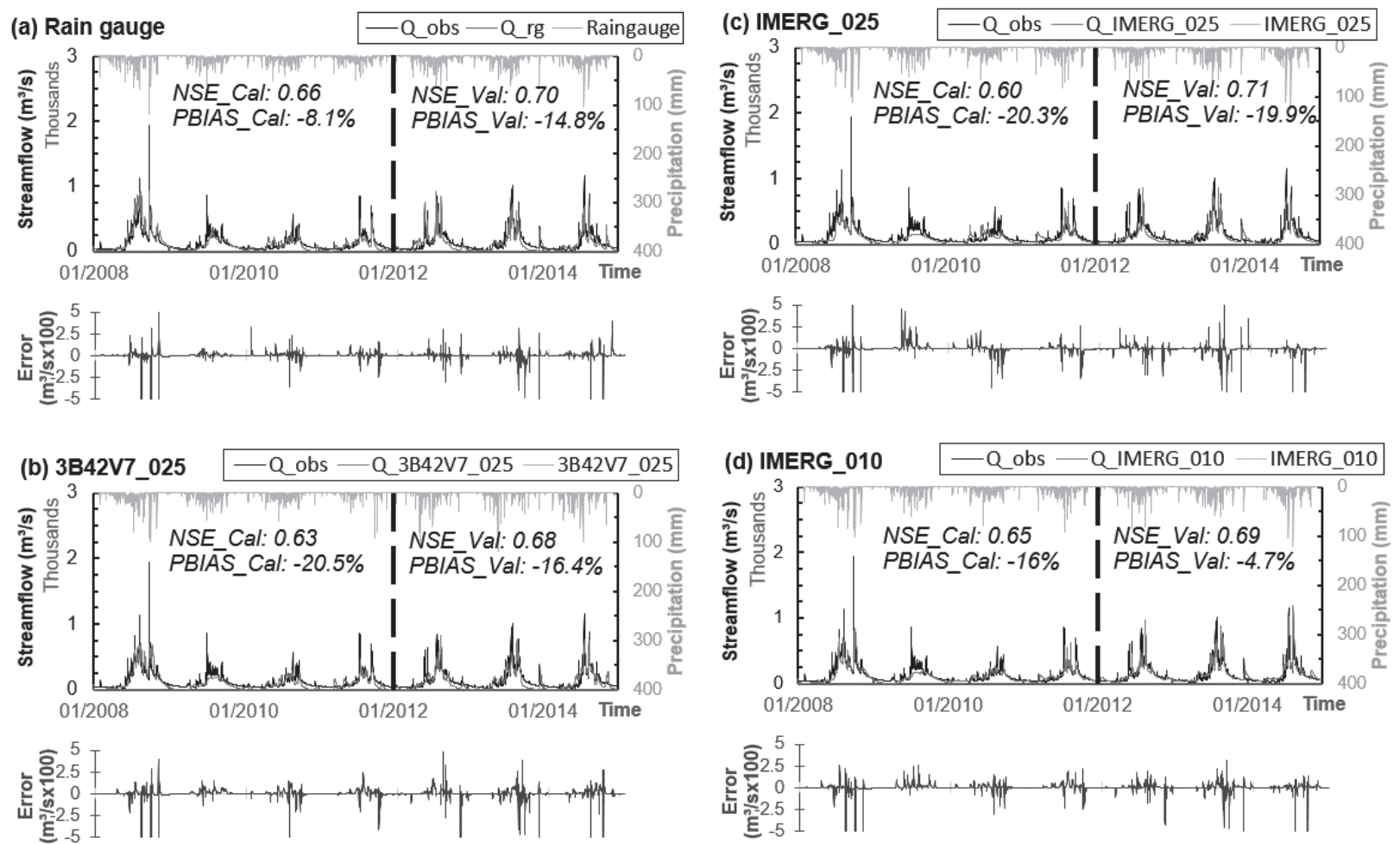

Fig. 6. Comparison between observed and simulated streamflow based on a) Rain gauge, b) 3B42V7_025, c) IMERG_025, and d) IMERG 010 at Xala basin. Calibration period is from 2008-2011 while the validation period is from 2012-2014. Error panel shows the difference between observed and simulated values varying in time.

rain gauge data and satellite-based rainfall exhibited a considerably low bias.

In each temporal variation plot between observed and simulated streamflow plot, a small panel that revealed the difference between observed and simulated streamflow at daily time intervals was also added. It is noticed that errors seem to vary constantly during simulation periods, demonstrating a likely normal distribution for streamflow simulation errors with all models forced with different rainfall inputs. 

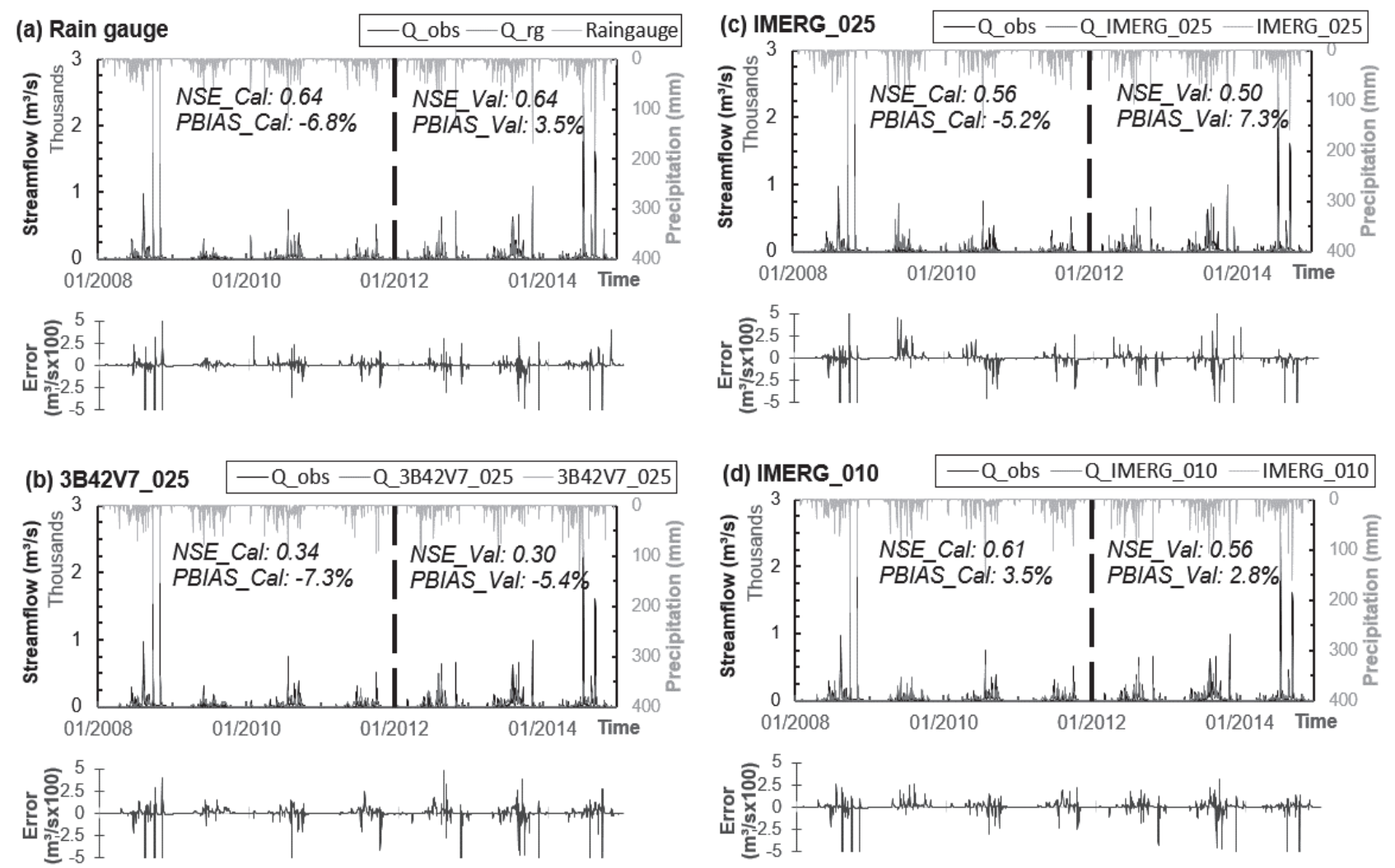

Fig. 7. Comparison between observed and simulated streamflow based on a) Rain gauge and b) 3B42V7_025, c) IMERG_025, and d) IMERG_010 at Langson basin. Calibration period is from 2008-2011 while the validation period is from 2012-2014. Error panel shows the difference between observed and simulated values varying in time.

\section{Conclusions}

This study aims to examine the improvement of IMERG in Northern Vietnam by (i) comparing this product with 53 rain gauge and (ii) forcing into the hydrological SWAT model to simulate streamflow. This study used TMPA 3B427- the predecessor of IMERG as a benchmark case. We used four different rainfall metrics (Correlation Coefficient (CC), Root Mean Square Error (RMSE), Probability of Detection (POD), and False Alarm Ratio (FAR)) and two streamflow metrics (Nash-Sutcliffe Efficiency (NSE) and Percentage Bias (PBIAS)) to evaluate satellitebased rainfall performances. The results indicated that IMERG were better than TMPA 3B42V7 in CC, RMSE, POD, but not in FAR. With respect to streamflow simulation, IMERG achieved a comparable performance as rain gauge measurements as input as the SWAT hydrological model in simulating streamflow at two river basins located in Northern Vietnam.

When this study downscaled IMERG (from $0.10^{\circ}$ to $0.25^{\circ}$ ), rainfall performance metrics did not exhibit significant differences. However, the streamflow simulations with SWAT based on lower resolution IMERG dataset, were less skilled than SWAT based on original IMERG dataset. Overall, the performance of GPM IMERG is sufficient for estimating the water resources as well as simulating streamflow for hydrological applications.

\section{Acknowledgements}

This study is partly supported from Thuyloi University. The authors would like to express our sincere gratitude to Vietnam Hydrology and Meteorological Administration for providing ground data needed in this study. The authors also thank anonymous reviewers for their constructive comments.

\section{Conflict of Interest}

The authors declare no conflict of interest.

\section{References}

1. STRANGEWAYS I. Precipitation: theory, measurement and distribution. Cambridge University Press, 302, 2006.

2. TAPIADOR F.J., TURK F.J., PETERSEN W., HOU A.Y., GARCÍA-ORTEGA E., MACHADO L.A., ANGELIS C.F., SALIO P., KIDD C., HUFFMAN G.J. Global precipitation measurement: Methods, datasets and applications. Atmospheric Research 104, 70, 2012. 
3. SUN Q., MIAO C., DUAN Q., ASHOURI H., SOROOSHIAN S., HSU K.L. A review of global precipitation data sets: Data sources, estimation, and intercomparisons. Reviews of Geophysics, 2018.

4. MICHAELIDES S., LEVIZZANI V., ANAGNOSTOU E., BAUER P., KASPARIS T., LANE J. Precipitation: Measurement, remote sensing, climatology and modeling. Atmospheric Research 94, 512, 2009.

5. HUFFMA G. 'IMERG Quality Index,' in Book IMERG Quality Index, edited by Editor. City, 2018.

6. LE M.-H., LAKSHMI V., BOLTEN J., BUI D.D. Adequacy of Satellite-derived Precipitation Estimate for Hydrological Modeling in Vietnam Basins. Journal of Hydrology 586, 124820, 2020.

7. HUFFMAN G.J., BOLVIN D.T., NELKIN E.J., WOLFF D.B., ADLER R.F., GU G., HONG Y., BOWMAN K.P., STOCKER E.F. The TRMM multisatellite precipitation analysis (TMPA): Quasi-global, multiyear, combinedsensor precipitation estimates at fine scales. Journal of Hydrometeorology 8, 38, 2007.

8. DARAND M., AMANOLLAHI J., ZANDKARIMI S. Evaluation of the performance of TRMM Multi-satellite Precipitation Analysis (TMPA) estimation over Iran. Atmospheric Research 190, 121, 2017.

9. DINH K.D., ANH T.N., NGUYEN N.Y., BUI D.D., SRINIVASAN R. Evaluation of Grid-Based Rainfall Products and Water Balances over the Mekong River Basin. Remote Sensing 12, 2020.

10. LE H., SUTTON J., BUI D., BOLTEN J., LAKSHMI V. Comparison and Bias Correction of TMPA Precipitation Products over the Lower Part of Red-Thai Binh River Basin of Vietnam. Remote Sensing 10, 1582, 2018.

11. LI D., CHRISTAKOS G., DING X., WU J. Adequacy of TRMM satellite rainfall data in driving the SWAT modeling of Tiaoxi catchment (Taihu lake basin, China). Journal of hydrology 556, 1139, 2018.

12. HUFFMAN G.J., BOLVIN D.T., BRAITHWAITE D., HSU K., JOYCE R., XIE P., YOO S.-H. NASA global precipitation measurement (GPM) integrated multi-satellite retrievals for GPM (IMERG). Algorithm theoretical basis document, version 4, 30, 2014.

13. HOU A.Y., KAKAR R.K., NEECK S., AZARBARZIN A.A., KUMMEROW C.D., KOJIMA M., OKI R., NAKAMURA K., IGUCHI T. The global precipitation measurement mission. Bulletin of the American Meteorological Society 95, 701, 2014.

14. SKOFRONICK-JACKSON G., PETERSEN W.A., BERG W., KIDD C., STOCKER E.F., KIRSCHBAUM D.B., KAKAR R., BRAUN S.A., HUFFMAN G.J., IGUCHI T. The Global Precipitation Measurement (GPM) mission for science and society. Bulletin of the American Meteorological Society 98, 1679, 2017.

15. HUFFMAN G.J., BOLVIN D.T., NELKIN E.J. Integrated Multi-satellitE Retrievals for GPM (IMERG) technical documentation. NASA/GSFC Code 612, 47, 2018.

16. YU L., MA L., LI H., ZHANG Y., KONG F., YANG Y. Assessment of high-resolution satellite rainfall products over a gradually elevating mountainous terrain based on a high-density rain gauge network. International Journal of Remote Sensing 41, 5620, 2020.

17. GILEWSKI P., NAWALANY M. Inter-Comparison of Rain-Gauge, Radar, and Satellite (IMERG GPM) Precipitation Estimates Performance for Rainfall-Runoff Modeling in a Mountainous Catchment in Poland. Water 10, 1665, 2018.
18. OMRANIAN E., SHARIF H.O. Evaluation of the global precipitation measurement (GPM) satellite rainfall products over the lower Colorado River basin, Texas. JAWRA Journal of the American Water Resources Association 54, 882, 2018.

19. TANG G., CLARK M.P., PAPALEXIOU S.M., MA Z., HONG Y. Have satellite precipitation products improved over last two decades? A comprehensive comparison of GPM IMERG with nine satellite and reanalysis datasets. Remote Sensing of Environment 240, 111697, 2020.

20. MASTRANTONAS N., BHATTACHARYA B., SHIBUO Y., RASMY M., ESPINOZA-DÁVALOS G., SOLOMATINE D. Evaluating the Benefits of Merging Near-Real-Time Satellite Precipitation Products: A Case Study in the Kinu Basin Region, Japan. Journal of Hydrometeorology 20, 1213, 2019.

21. NGUYEN CHI NGHIA, DUONG B.D. 'Overview of transboundary waters in Vietnam,' in Book Overview of transboundary waters in Vietnam, edited by Editor. City, 2016.

22. NGUYEN T.H., MASIH I., MOHAMED Y.A., VAN DER ZAAG P. Validating Rainfall-Runoff Modelling Using Satellite-Based and Reanalysis Precipitation Products in the Sre Pok Catchment, the Mekong River Basin. Geosciences 8, 164, 2018.

23. VU T.M., RAGHAVAN S.V., LIONG S.Y., MISHRA A.K. Uncertainties of gridded precipitation observations in characterizing spatio-temporal drought and wetness over Vietnam. International Journal of Climatology 38, 2067, 2018.

24. ARNOLD J.G., MORIASI D.N., GASSMAN P.W., ABBASPOUR K.C., WHITE M.J., SRINIVASAN R., SANTHI C., HARMEL R., VAN GRIENSVEN A., VAN LIEW M.W. SWAT: Model use, calibration, and validation. Transactions of the ASABE 55, 1491, 2012.

25. HA L.T., BASTIAANSSEN W.G., GRIENSVEN A.V., VAN DIJK A.I., SENAY G.B. Calibration of Spatially Distributed Hydrological Processes and Model Parameters in SWAT Using Remote Sensing Data and an AutoCalibration Procedure: A Case Study in a Vietnamese River Basin. Water 10, 212, 2018.

26. VU M., RAGHAVAN S., LIONG S.-Y. Use of Regional Climate Models for Proxy Data over Transboundary Regions. Journal of Hydrologic Engineering 21, 05016010, 2016.

27. VU T.T., DAO N.K., DO Q.L. Using gridded rainfall products in simulating streamflow in a tropical catchment - A case study of the Srepok River Catchment, Vietnam. Journal of Hydrology and Hydromechanics 65, 18, 2017.

28. NGUYEN D.N., NGUYEN T.H. Climate and Climate Resources in Vietnam. Agricultural Publishing House: Hanoi, Vietnam, 296, 2004 [In Vietnamese].

29. ARNOLD J.G., SRINIVASAN R., MUTTIAH R.S., WILLIAMS J.R. Large area hydrologic modeling and assessment part I: model development 1. JAWRA Journal of the American Water Resources Association 34, 73-89, 1998.

30. NATIONAL INSTITUTE FOR SOILS AND FERTILIZERS. The basic information of main soil units of Vietnam. The Gioi Publishers: Hanoi, Vietnam,pp. 2002.

31. ZALAKI-BADIL N., ESLAMIAN S., SINGH V.P., OSTAD-ALI-ASKARI K., DALEZIOS N.R., DEHGHAN S. Calibration and Uncertainty of the SWAT Model Using the SUFI-2 Algorithm. 
32. CHUA Z.-W., KULESHOV Y., WATKINS A. Evaluation of Satellite Precipitation Estimates over Australia. Remote Sensing 12, 678, 2020.

33. MORIASI D.N., ARNOLD J.G., VAN LIEW M.W., BINGNER R.L., HARMEL R.D., VEITH T.L. Model evaluation guidelines for systematic quantification of accuracy in watershed simulations. Transactions of the ASABE 50, 885, 2007.
34. LE M.-H., KIM H., MOON H., ZHANG R., LAKSHMI V., NGUYEN L.-B. Assessment of drought conditions over Vietnam using standardized precipitation evapotranspiration index, MERRA-2 re-analysis, and dynamic land cover. Journal of Hydrology: Regional Studies 32, 100767, 2020.

\section{Supplementary Material}

Supplementary A. Description of coordinates for rain gauges used in this study.

\begin{tabular}{|c|c|c|c|c|c|c|c|c|c|c|c|}
\hline ID & NAME & LAT & LONG & ID & NAME & LAT & LONG & ID & NAME & LAT & LONG \\
\hline 1 & Backan & 22.13 & 105.82 & 21 & Kimboi & 20.67 & 105.53 & 41 & Thuanchau & 21.43 & 103.7 \\
\hline 2 & Bacninh & 21.2 & 106.05 & 22 & Lang & 21.02 & 105.85 & 42 & Thuongtin & 20.9 & 105.883 \\
\hline 3 & Baichay & 20.97 & 107.03 & 23 & Langson & 21.83 & 106.77 & 43 & Tienyen & 21.33 & 107.44 \\
\hline 4 & Baolac & 22.95 & 105.67 & 24 & Laocai & 22.5 & 103.95 & 44 & Tuangiao & 21.58 & 103.42 \\
\hline 5 & Batbat & 21.18 & 105.32 & 25 & Locbinh & 21.77 & 106.92 & 45 & Tuky & 20.8 & 106.4 \\
\hline 6 & Bavi & 21.08 & 105.37 & 26 & Maichau & 20.6 & 105.07 & 46 & Tuly & 20.567 & 105.25 \\
\hline 7 & Caobang & 22.67 & 106.23 & 27 & Mongcai & 21.52 & 107.97 & 47 & Vanmich & 22.1 & 106.37 \\
\hline 8 & Caophong & 20.7 & 105.32 & 28 & Muongte & 22.47 & 102.63 & 48 & Vietlam & 22.6 & 104.933 \\
\hline 9 & Cauram & 20.68 & 105.67 & 29 & Ninhbinh & 20.27 & 105.98 & 49 & Vinhyen & 22.383 & 104.45 \\
\hline 10 & Chilang & 21.65 & 106.57 & 30 & Phadin & 21.57 & 103.52 & 50 & Xala & 20.94 & 103.92 \\
\hline 11 & Chilinh & 21.07 & 106.38 & 31 & Phuxuyen & 20.77 & 105.9 & 51 & YenBai & 21.7 & 104.87 \\
\hline 12 & Dapday & 21.08 & 105.65 & 32 & Quynhnhai & 21.85 & 103.57 & 52 & Yenbinh & 22.433 & 104.583 \\
\hline 13 & Dienbien & 21.4 & 103.02 & 33 & Sinho & 22.37 & 103.23 & 53 & Yenlap & 20.55 & 106.5 \\
\hline 14 & Dinhlap & 21.5333 & 107.1 & 34 & Songma & 21.05 & 103.75 & & & & \\
\hline 15 & Donganh & 21.13 & 105.87 & 35 & Sonla & 21.33 & 103.9 & & & & \\
\hline 16 & Hagiang & 22.82 & 104.98 & 36 & Sontay & 21.13 & 105.5 & & & & \\
\hline 17 & Haiduong & 20.95 & 106.3 & 37 & Tamduong & 22.05 & 103.15 & & & & \\
\hline 18 & Hoabinh & 20.82 & 105.33 & 38 & Thainguyen & 21.6 & 105.5 & & & & \\
\hline 19 & Huongson & 20.62 & 105.79 & 39 & Thanhba & 21.517 & 105.117 & & & & \\
\hline 20 & Hungthi & 20.52 & 105.67 & 40 & Thatkhe & 22.25 & 106.47 & & & & \\
\hline
\end{tabular}


